\title{
A Hunter-Gatherer Exercise Prescription to Optimize Health and Well-Being in the Modern World
}

\author{
Evan L. O’Keefe ${ }^{1} \cdot$ Carl J. Lavie ${ }^{1,2}$
}

Received: 21 January 2020 / Accepted: 23 September 2020 / Published online: 27 October 2020

(c) Beijing Sport University 2020

\begin{abstract}
There has been considerable innovation and advancement in the field of exercise and physical activity (PA). In regards to the battle against chronic non-communicable disease, however, we believe the model of PA that would prove most salutary is one closely mimicking that of our hunter-gatherer ancestors. For the purpose of longevity, the human body and our genetic makeup have been evolutionarily adapted to respond best to moderate amounts of high-intensity interval training, in conjunction with high amounts of low intensity exercise. Moreover, to optimize resiliency and cardiorespiratory fitness, a hunter-gatherer fitness regimen must include cross training targeted at flexibility, balance and strength. Though not commonly understood, the health benefits from exercise comprise a reverse J-curve. The endurance athletes residing on the furthest reaches of the PA spectrum appear to lose a substantial portion of the exercise-related longevity and cardiovascular benefits due to cardiac overuse injury. Conversely, there is an emerging body of evidence suggesting leisure time exercise done with peers in a natural environment is significantly superior to that training done in solitude. This idea of the "power of play" lends support to the ancestral model of PA whereby humans are evolutionary adapted to be highly social, outdoor creatures capable of a diverse range of PA at varying intensities.
\end{abstract}

Keywords Hunter-gatherer $\cdot$ Cardiovascular disease $\cdot$ Physical activity $\cdot$ Exercise

$\begin{array}{ll}\text { Abbreviations } \\ \text { AF } & \text { Atrial fibrillation } \\ \text { BMI } & \text { Body mass index } \\ \text { BP } & \text { Blood pressure } \\ \text { CAC } & \text { Coronary artery calcium } \\ \text { CHD } & \text { Coronary heart disease } \\ \text { CRF } & \text { Cardiorespiratory fitness } \\ \text { CV } & \text { Cardiovascular } \\ \text { CVD } & \text { Cardiovascular disease } \\ \text { HIIT } & \text { High-intensity interval training } \\ \text { MET } & \text { Metabolic equivalent } \\ \text { PA } & \text { Physical activity } \\ \text { PAG } & \text { Physical activity guidelines } \\ \text { RE } & \text { Resistance exercise }\end{array}$

Carl J. Lavie

clavie@ochsner.org

1 Ochsner Clinical School, The University of Queensland School of Medicine, New Orleans, LA, USA

2 Department of Cardiovascular Diseases, John Ochsner Heart and Vascular Institute, 1514 Jefferson Highway, New Orleans, LA 70121-2483, USA

\section{T2D Type 2 diabetes}

US United States

\section{Introduction}

The environments in which early humans evolved were often challenging, and thus their lifestyles were physically demanding. Male and female hunter-gatherers would typically take 16,000 and 17,000 steps (about eight miles) per day, respectively; and cardiovascular (CV) disease (CVD) was rare even among older individuals in the tribe [29]. In contrast, the average adult in the United States (US) today gets about 5000 steps per day, and CVD remains the leading cause of death [57]. In the US in 2019 more than 80\% of the adult population is not meeting the physical activity (PA) guidelines (PAG) [57], children are spending more than $7.5 \mathrm{~h}$ a day in front of a screen [62] and physical inactivity has surged to the $4^{\text {th }}$ leading cause of death with obesity trending at 5 th [16].

The day-to-day lifestyle for nearly all modern humans has transitioned to a sedentary, indoor existence. Scientific advancements over the past century bestowed dramatic 
decreases in infant mortality, and deaths due infection, accidents, violence and starvation-all of which has translated into exponential improvements in longevity. From 1900 to 2014 the global average life expectancy increased from 31 to 72 ; ironically during that time we have also witnessed the blossoming of a worldwide pandemic of chronic disease $[24,61]$-mortality from communicable disease has fallen from approximately 15 to 10 million deaths per annum, but non-communicable disease has steadily risen from 26 to 41 million deaths per annum [63]. Overweight and obesity now affect nearly $75 \%$ of the American populace, and it's imperative that humanity reintroduces PA, particularly in outdoor settings, into the weekly routine [25].

Cardiorespiratory fitness (CRF) has consistently been shown to be one of the strongest determinates of long-term fitness and survival $[8,11,33,66]$. Yet, the debate rages on regarding the mode of exercise best suited to confer these benefits. A large body of evidence clearly shows that we are evolutionarily adapted to be physically active throughout our lifespan, and our physical and mental health are optimized when we incorporate PA into our daily routine [9, 23]. Paradoxically, excessive doses of high-intensity endurance exercise have been linked to cardiac remodeling, myocardial fibrosis, arrhythmias and increased coronary artery calcification (CAC) [23, 53]. Current human physiology is a byproduct of extensive evolutionary adaptation that maximized our chances of survival in the wilderness in the context of a small group of physically active, socially interconnected individuals. An exercise regime mimicking that pattern of PA would seemingly be the ideal template from which to design a modern exercise regimen. With the integration of recent studies on group exercise, it is our belief that consistent amounts of low to moderate PA intermixed with moderate amounts of moderate to high intensity PA, done in conjunction with peers, friends and family in an outdoor scene, is the model of PA that is best suited to address the obesity epidemic.

\section{Hunter-Gatherer Exercise Regimen}

For tens-of-thousands of generations our ancestors obligatorily exerted moderate to high levels of energy on a daily basis, hunting and foraging for natural unprocessed foods, building and maintaining their shelters, procuring water and protecting themselves from predators, enemies, and the elements [56]. While it is difficult to draw conclusions about past peoples in comparison to contemporary societies, the remote reaches of the Bolivan forests provide tangential evidence. The Tsimane are a very social, indigenous tribe subsisting on hunting, fishing and farming who generally obtain approximately 15,000 steps a day. In a study from Kaplan et al. [29], 596 (85\%) of 705 Tsimane had no coronary artery calcium (CAC). In those aged 75 or older, 31 (65\%) of individuals had a CAC score of 0 and only four (8\%) had CAC scores of 100 or more-a five-fold reduction in prevalence as compared to industrialized populations $(P \leq 0.0001)$. Mean LDL and HDL cholesterol concentrations were $91 \mathrm{mg} / \mathrm{dL}$ and $39.5 \mathrm{mg} / \mathrm{dL}$, respectively. Moreover, obesity, hypertension, high blood sugar, and regular cigarette smoking were rare [29]. Alternatively, Kim Hill, an Arizona State University anthropologist, accrued nearly 30 years of experience living amongst modern day hunter-gatherer tribes. His work predominately focused on the Ache of Paraguay, the Hiwi of southwestern Venezuela and the Mashco-Piro, Yora and Machiguenga of Peru. He describes their lifestyle:

"Recent GPS data I collected with (the Ache) suggests that about $10 \mathrm{~km}$ per day is probably closer to their average distance covered during search. They might cover another $1-2 \mathrm{~km}$ per day in very rapid pursuit... Basically they do moderate days most of the time, and sometimes really hard days usually followed by a very easy day.

The Hiwi on the other hand only hunted about 2-3 days a week and often told me they wouldn't go out on a particular day because they were 'tired'. They would stay home and work on tools, etc.

...the Ache do converse and even sing during some of their search... Basically, men talk to each other until the speed gets up around $3 \mathrm{~km} / \mathrm{h}$ which is a very tough pace in thick jungle. Normal search is more like about $1.5 \mathrm{~km} / \mathrm{h}$, a pretty leisurely pace. Monkey hunts can also be very strenuous because they consist of bursts of sprints every 20-30 s (as the monkeys are flushed and flee to new cover), over a period of an hour or two without a rest.

Many of the (Ache) in their mid-30 s to mid-50 s showed great aerobic conditioning compared to Americans of that age. While hunter-gatherers are generally in good physical condition if they haven't yet been exposed to modern diseases and diets that come soon after permanent outside contact, I would not want to exaggerate their abilities. They are what you would expect if you took a genetic cross section of humans and put them in lifetime physical training at moderate to hard levels."

In stark comparison, the Baka people of Cameroon have been documented devoting $70 \%-80 \%$ of their waking hours to resting activities characterized by lying, sitting or standing with low concurrent heart rates. Still, in this community Yamauchi et al. recorded a prevalence of overweight individuals under 3\% and did not appreciate any obesity—theorized to be due to their outdoor existence characterized by habitual 
PA $[22,79]$. Our ancestral hunter-gatherers communities are thought to have been virtually free of obesity and chronic non-communicable disease in large part due to daily energy expenditures of 800-1200 kcal-3-5 times the total energy expenditure of the average American [13, 17].

\section{Interval and Cross Training}

A hunter-gatherer existence is marked by diverse physicality and consecutive days of light to moderate PA, occasional days of strenuous exertion being followed by relatively easy days of rest and relaxation. The unpredictability of the hunt closely resembles modern day high-intensity interval training (HIIT). As Dr. Hill recounted, with the pace dictated by the prey, these hunter-gatherers carried speeds varying from a slow walk to a full sprint for 20-30 s over changing terrain. This aerobic conditioning typically fell within $5-15 \mathrm{~km}$ a day - roughly equivalent to at least 10,000 steps a day ( $8 \mathrm{~km}$ or 5 miles per day), a dose of PA that has been recently verified as target dose of exercise that correlates with health well-being $[6,56,65]$.

There are three ways to increase levels of aerobic capacity-increase exercise frequency, duration or most importantly intensity [43]. As compared to continuous endurance training, evidence shows HIIT promotes greater visceral weight loss, better glycemic control with improved overall levels of CRF and corticotropin-releasing factor [27, 56, 74]. As for cardiac benefits, while both modes induce similar decreases to systolic blood pressure (BP), HIIT demonstrates a greater reduction in resting heart rate with improved cardiac structure and function [14, 31].

Humans living ancestral, pre-industrial lifestyles not only exhibited diversity in their aerobic PA but by necessity also engaged in activities that augmented fitness across several domains. Daily exertion entailed constructing, climbing, carrying, butchering, leaping, digging, and picking amongst others [55]. Whereas the hunt resembled HIIT, these activities of daily life required feats of strength and flexibility akin to cross training. The multifaceted nature of this regimen is of critical importance as it produces higher levels of CRF while conferring resiliency and minimizing likelihood of injury [10]. Thus, cross training has been long hailed as a superior form of exercise widely utilized by fitness coaches to condition all levels of athletes $[42,76]$.

\section{Obesity and Ameliorating Effects of PA}

Human lifestyles became progressively more sedentary after the industrial revolution of the 18th and 19th centuries in comparison to the innately active existence of our Paleolithic ancestors whose 'full-time jobs' were to hunt, forage and maintain communities in the wilderness. Accordingly, these technological advancements and "labor-saving" devices gave way to the systemic obesity we are now witnessing in contemporary society in large part due to a population in which the majority of its constituents no longer receive adequate amounts of aerobic exercise each week (Fig. 1).

Three-fourths of American adults are overweight or obese with childhood obesity steadily climbing over the last 50 years to a recent high of $18.5 \%[12,25]$. Obesity is independently associated with dyslipidemia, hypertension, and glucose regulation abnormalities-both metabolic syndrome (MetS) and type 2 diabetes (T2D). Further, all of the preceding are risk factors for CVD, which remains the predominate cause of death in the US, accounting for $41 \%$ of fatalities each year [20]. Obesity is also associated with neurohormonal disruptions such as renin-angiotensin aldosterone system activation, sympathetic over-stimulation and hyperleptinemia, as well as instigation of a persistent low-level inflammatory state. Adipose tissue produces tumor necrosis factor- $\alpha$ and interleukin- $1 \mathrm{~b}$, amongst other inflammatory cytokines, which help propagate CVD, coronary heart disease (CHD), and Alzheimer's disease, in particular [18].

PA continues to stand as a formidable weapon in the arsenal against obesity and chronic disease. In 2010, the American Heart Association released a set of seven cardinal health metrics that largely determine CVD. These guidelines are comprised of four health behaviors (non-smoking, body mass index $[\mathrm{BMI}]<25 \mathrm{~kg} / \mathrm{m}^{2}$, PA at goal levels, and adherence to a recommended diet), and three health factors (untreated total cholesterol $<200 \mathrm{mg} / \mathrm{dL}$, untreated $\mathrm{BP}<120 / 80 \mathrm{mmHg}$, and fasting blood glucose $<100 \mathrm{mg} / \mathrm{dL}$ ) [41]. PA, however, has far-reaching effects on obesity status, $\mathrm{BP}$, lipid concentrations and glucose regulation. Thus, targeting this major determinant-exercise-is "one stone that can kill many birds" in the fight against non-communicable disease.

Low PA is independently associated with CVD along with a host of other chronic diseases, such as colon cancer, breast cancer, T2D, depression and anxiety and Alzheimer's $[36,39]$. Increased exercise tolerance/CRF and PA correlate with overall CV health and longevity; however, cardiorespiratory fitness is an even stronger predictor of prognosis than ET or PA alone [26, 58]. Although evidence demonstrates unfit individuals have a two- to three-fold increased risk of mortality across all levels of BMI [5], data from Kennedy and company suggests high levels of CRF have the potential to eliminate the elevated risk of CVD-related and all-cause mortality among the overweight and the obese [32]. Even so, studies from Barry et al. maintain that high CRF does not completely nullify the detrimental prognostic effects of BMI, with mortality rates for overweight fit and obese fit remaining $25 \%$ and $42 \%$ higher, respectively, compared to normal weight fit individuals [32]. 


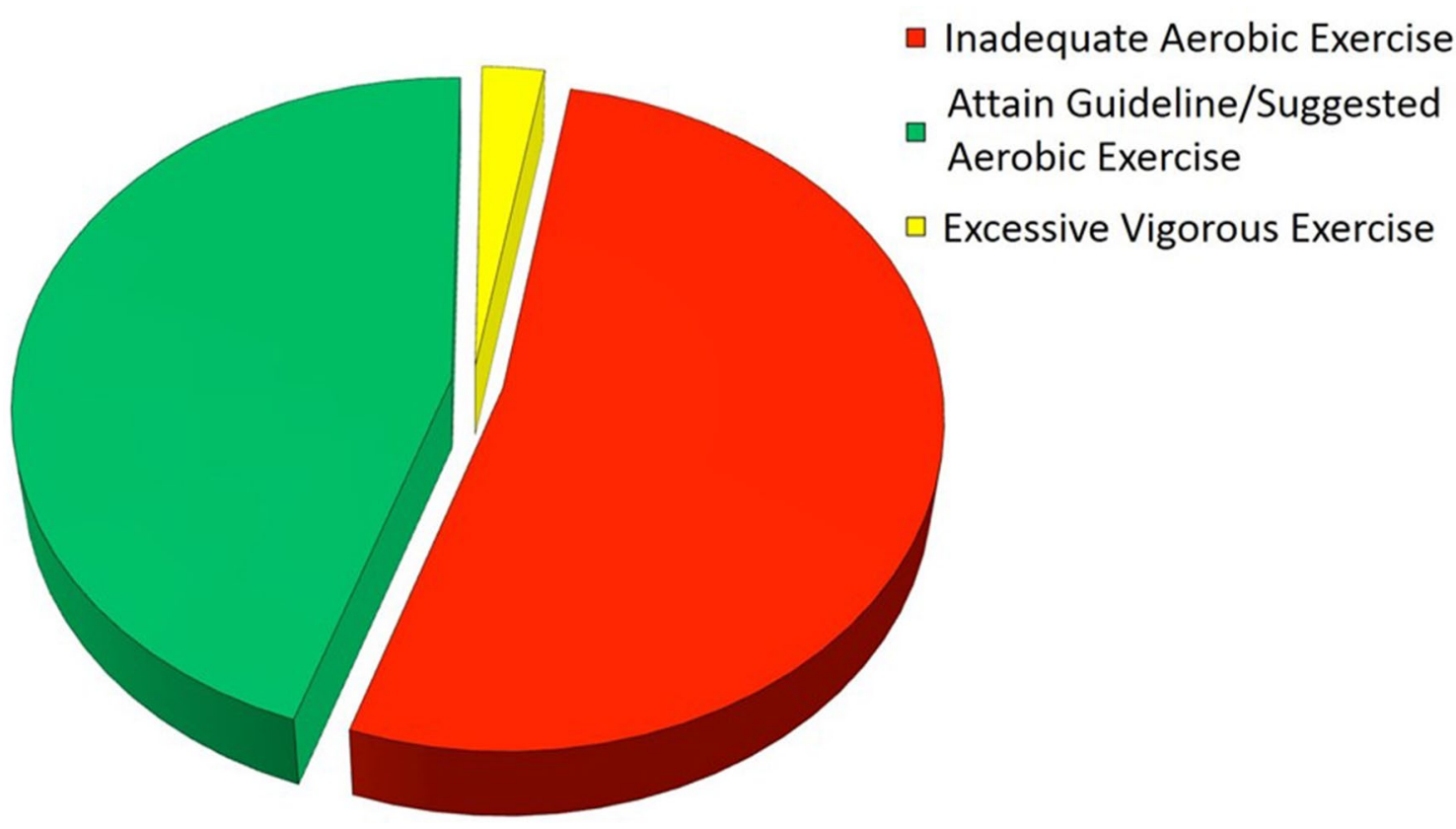

Fig. 1 Proportions of the US adult population habitually attaining (green), or not attaining (red) CDC PAG targets, and the cohort performing excessive strenuous exercise (yellow) [8, 9, 23]

So, while the best combination in terms of longevity is a normal weight individual with high CRF, incremental increases in CRF alone are associated with significant improvements in outcomes. Kodama presented evidence that every metabolic equivalent (MET) increase in CRF was associated with $13 \%$ and $15 \%$ decreases in all-cause and CVD-related mortality, respectively [33]. Subsequent studies by Lee et al. corroborated those findings with each MET gained inversely related to outcome reductions of $15 \%$ and 19\%, respectively [38]. After a 6 year follow up, those patients who presented with preserved CRF had a CVDrelated mortality reduction of $27 \%$ while those who had improved CRF received a $42 \%$ reduction [38]. Blair and colleagues reported that those who were initially slotted in the bottom quintile of CRF and showed improvement after 5 years, experienced a $52 \%$ reduction in CVD mortality in comparison to their matched counterparts who remained unfit [8].

\section{Goldilocks Zone of Exercise}

PA lies on a broad spectrum; and in general exercise promotes a healthy BMI, a reduction in chronic disease and overall improvements in longevity [8, 36, 52]. Moreover, exercise has remarkable mental health benefits; it reduces stress, improves sleep, and helps maintain a healthy diet and lifestyle including abstinence from tobacco [15, 64]. The relationship between exercise and derived benefit, however, is not linear but, more accurately, a reverse J-curve. There is a small, yet distinct, population of long-term endurance athletes that not only demonstrate an elevated incidence of CHD (Fig. 2), but, ultimately, lose a portion of the longevity and CV benefits of PA due to cardiac overuse injury (Fig. 3) $[1,2,21,35,37,45,46,49,50,52,54,67,68,70,78]$.

This insidious syndrome, resulting from an accumulation of extended amounts of strenuous exercise, is most commonly witnessed in ultra-endurance athletes who have been training and racing for years to decades. Evidence from chronic marathon participants demonstrates significantly increased amounts of coronary artery plaque-both calcified and non-calcified-as compared to sedentary controls (Fig. 4) [44, 71]. The CARDIA study, a 25-year prospective cohort study examining over 3000 individuals, recently published data corroborating these findings. Their study found evidence showing that in comparison to individuals not meeting the Center of Disease Control (CDC) PAG, those attaining threefold or up to tenfold the amount of suggested exercise were $75 \%$ more likely to have CAC on CT scans [34]. Moreover, these ultra-endurance athletes predispose themselves to severe bradycardia, atrial and ventricular wall fibrosis, ventricular ectopy, premature cardiac aging, sudden cardiac death and atrial fibrillation (AF) with veteran endurance athletes having fivefold higher incidence of $\mathrm{AF}$ as compared to their sedentary counterparts $[30,51,53,59]$.

The Copenhagen City Heart study analyzed both male and female runners and found that those who selfidentified as runners had a 6-year increase in life expectancy 
Fig. 2 Hazard ratios (HRs) and $95 \%$ CIs for leisure time moderate-to vigorous-intensity physical activity and mortality [61]

Fig. 3 Absolute risks and 95\% CIs for CV events [24]
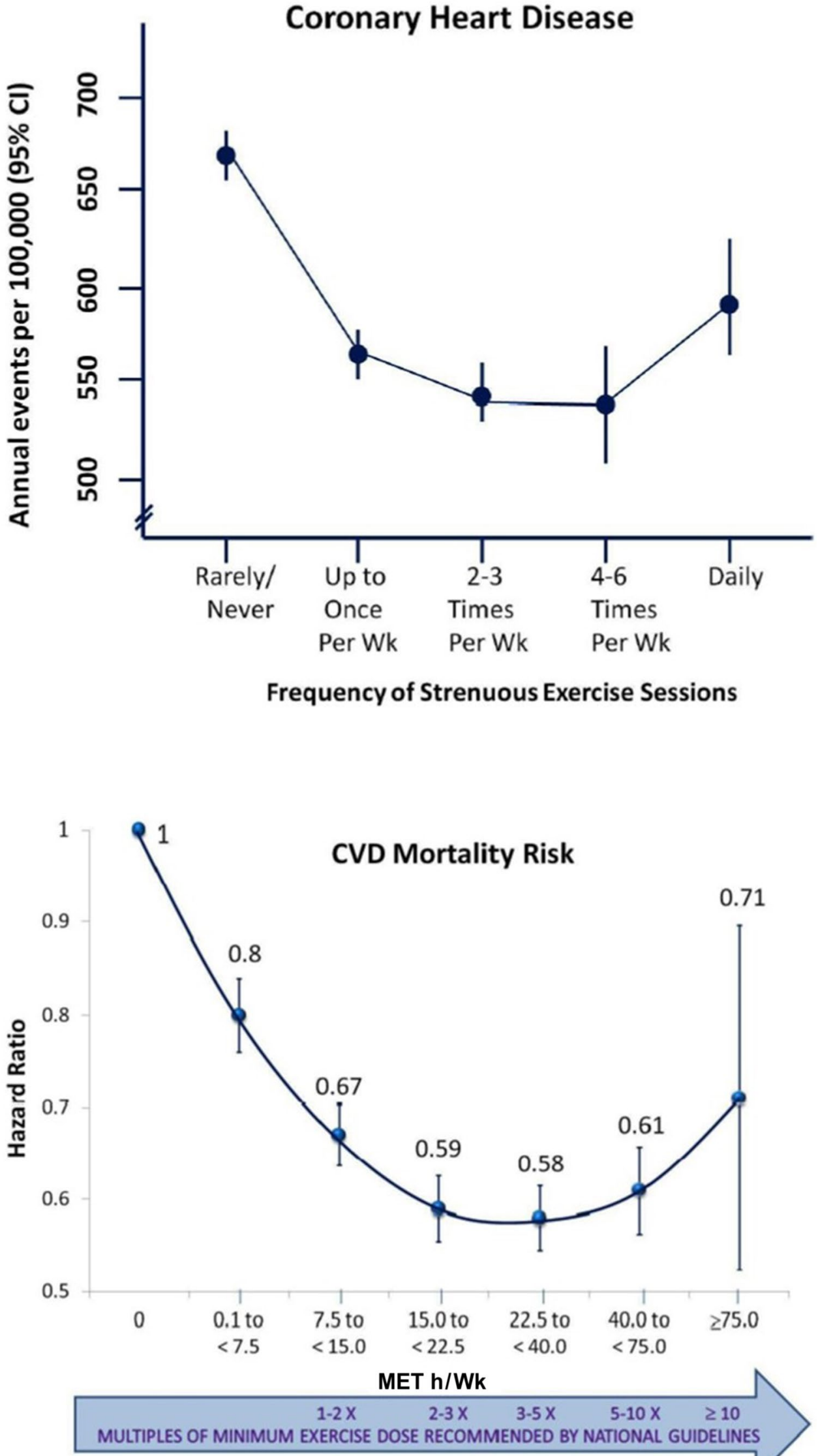
Fig. 4 The quantitative volumes of both calcified and noncalcified coronary plaques were higher in the marathoners than in sedentary controls [36]

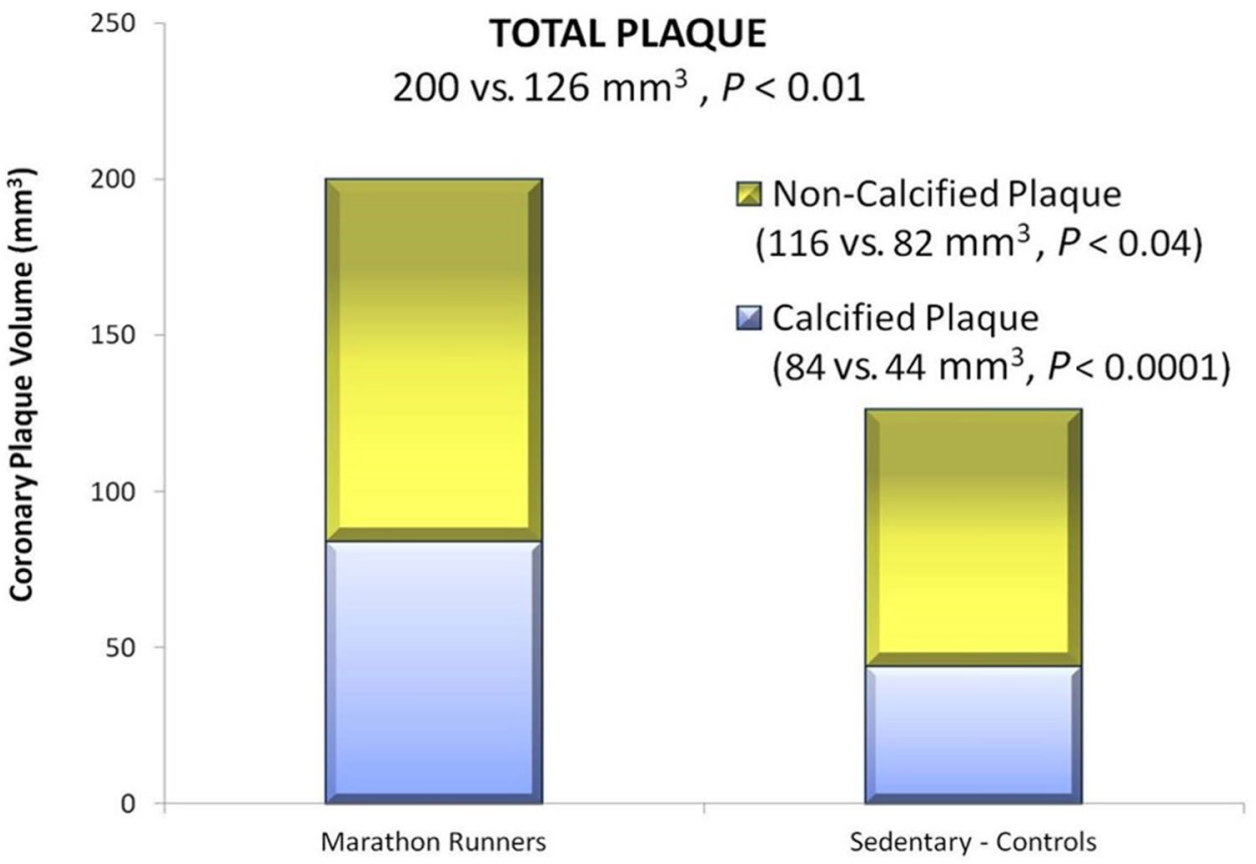

as compared to sedentary controls. Once again, a subgroup on the extreme high dose end of the PA spectrum who performed strenuous running - three or more sessions per week, at a faster pace, for a longer duration (mean of $>4 \mathrm{~h} /$ week) lost nearly the entire improvement in life expectancy associated with habitual light to moderate jogging [67, 68, 70]. On the other hand, for leisure time, non-strenuous PA, those who habitually performed light, moderate and high doses of PA had improvements in life expectancy of 2.8, 4.5 and 5.5 years, as compared to sedentary individuals. This indicates that a U-curve, or reverse $\mathrm{J}$, does not exist for leisure time activities such as gardening, housework, golf, doubles racquet sports, walking, bowling, leisurely cycling and dancing $[1,2,21,35,37,45,46,49,50,52,54,67,68,70,78]$.

Yet, this remains a pressing issue for as many as 17 million US adults who completed running competitions in 2016 (Fig. 5) [52]. The Million Women Study generated from the United Kingdom contained a cohort of 35,000 women $(3.5 \%$ of the total study group) who were undertaking strenuous exercise 7 days a week, and they displayed significantly elevated risks of $\mathrm{CHD}$, stroke and venous thromboembolism, compared to the women who took at least 1 day off per week from heart-pounding, sweat-producing exercise [2]. To put this issue into perspective, for every 20 individuals that are not meeting the CDC PAG there is one who is exercising excessively - approximately $2.5 \%$ of the population (Fig. 1) [49-51, 54].

It is often argued that it is irresponsible to publicize the potential dangers of excess exercise because it might discourage some of the $75 \%$ of sedentary people from starting an exercise regimen. This is analogous to arguing that we should not publicize the dangers of anorexia because it might discourage some of the $75 \%$ of overweight/obese American adults from pursuing weight loss. Although the cohort performing excessive doses of strenuous activity is a small proportion of the overall population, it probably comprises about 5 million adults in US. It is important for these individuals to understand that "more is not always better" when considering the ideal dose of exercise for health and longevity (Fig. 6) [48].

\section{Resistance Training}

The responsibilities of a tribe of hunter-gatherers invariably entailed manually constructing shelter, transporting resources like water and firewood, and carrying any spoils of a day's hunt back to camp. Independent of aerobic exercise, resistance exercise (RE) also called strength training, has also been associated with significantly reduced CVD events, morbidity and all-cause mortality [40]. Interestingly, this body of evidence is also demonstrating a reverse J-curve, similar to that of PA, where moderate amounts of RE are associated with the most benefit.

In 2019, the American College of Sports Medicine published a study using data from the Aerobics Center Longitudinal Study demonstrating a $40 \%-70 \%$ reduced risk of total CVD events [40]. In fact, as compared to the cohort with no recorded RE, for those performing RE just once a week the evidence showed a relative risk reduction of 0.28 (95\% CI 0.17-0.46) for total CVD events, 0.35 (95\% CI 0.19-0.63) for CVD morbidity, and 0.65 (95\% CI 0.44-0.97) 


\section{US Running Event Finishers 1990-2016}

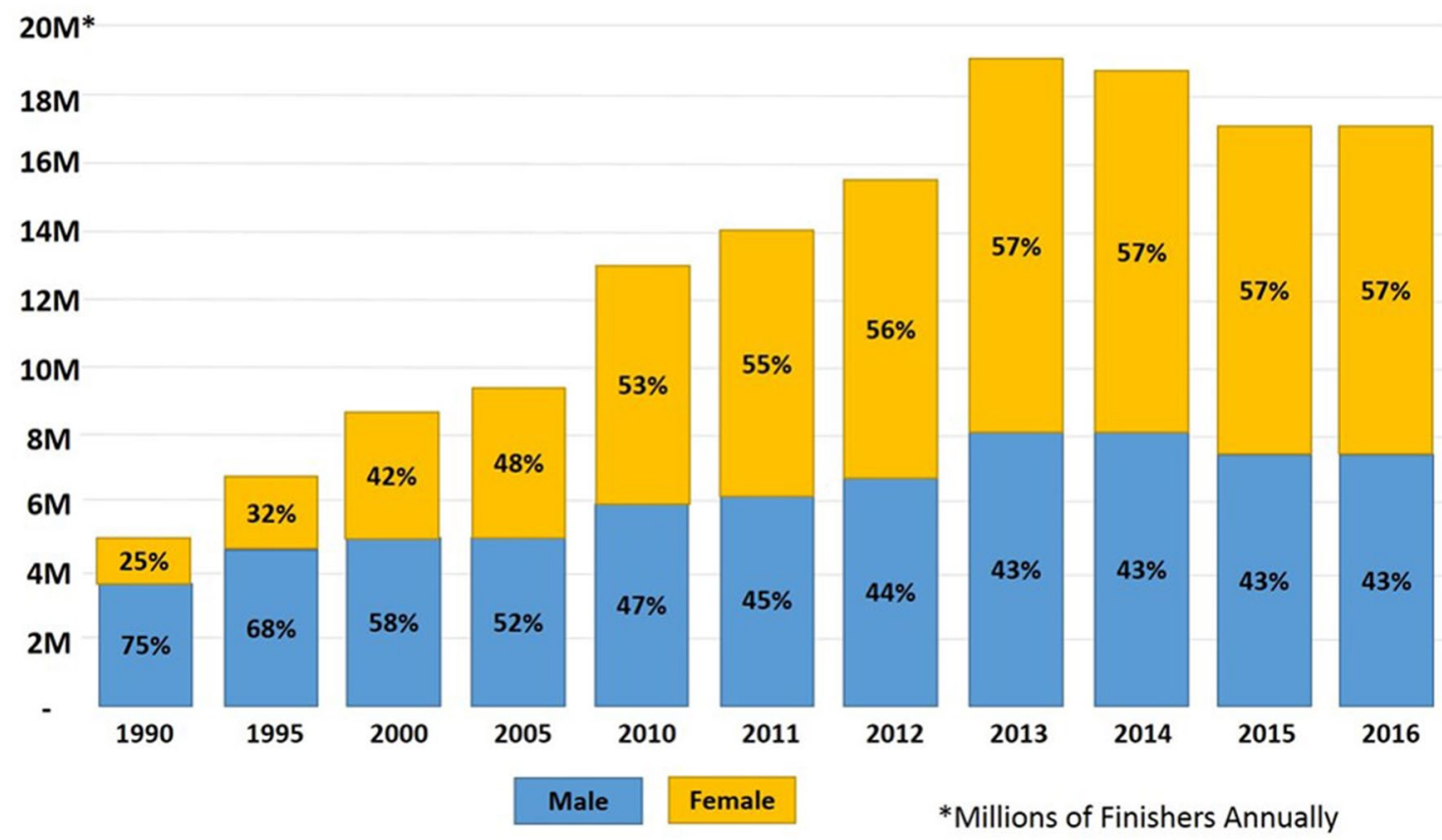

Fig. 5 Annual number of individuals (in millions) who completed running competitions in the US over the past quarter-century [41]

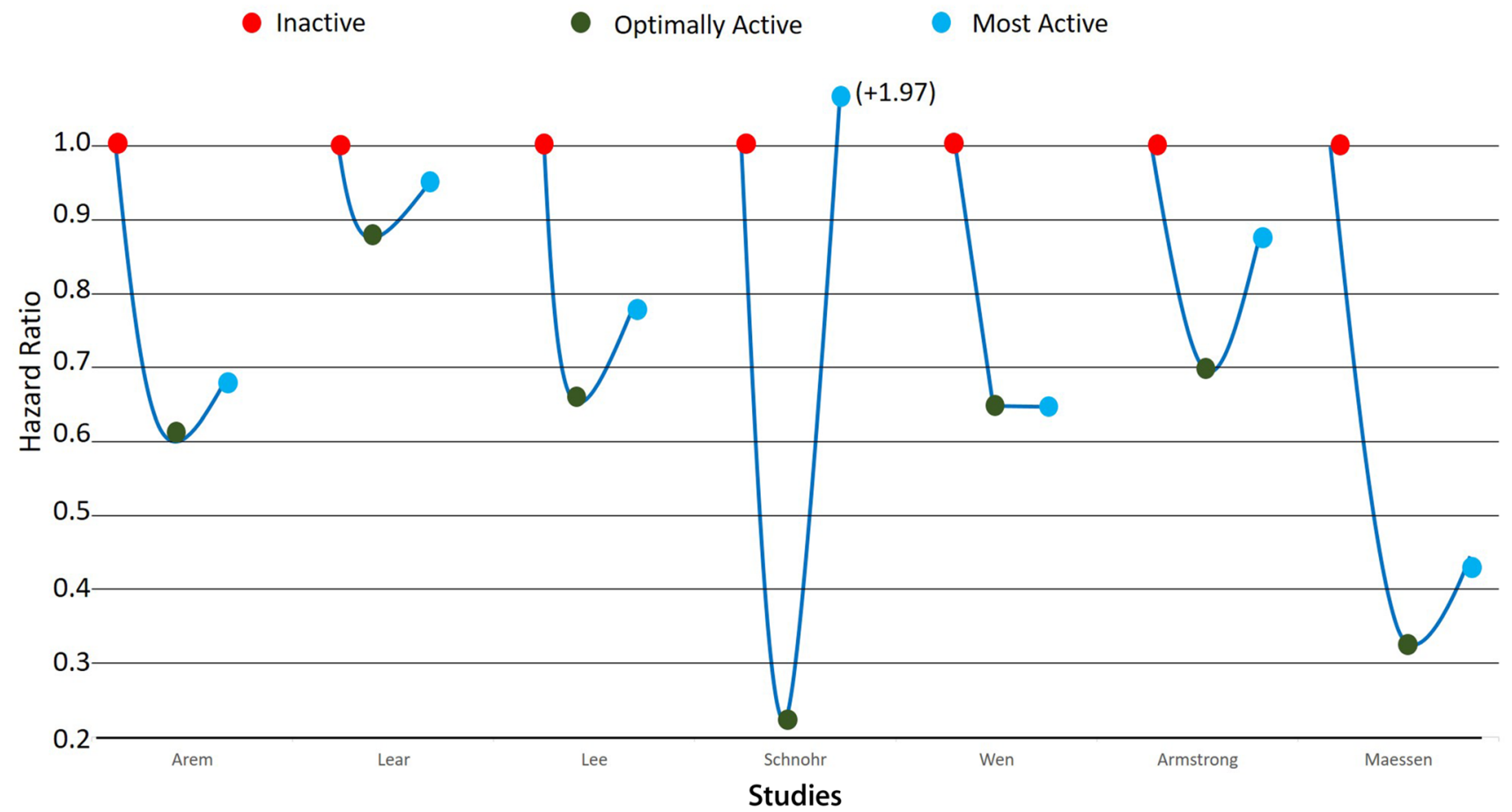

Fig. 6 Overview of curvilinear dose-response association between physical activity volume and CV health outcomes, specifically incident CVD and all-cause mortality [48]. Dot indicates incident CVD as outcome 
for all-cause mortality after adjustment for confounding variables [65]. Similar benefits were associated with those completing 1-59 min of RE per week, but beyond $60 \mathrm{~min} /$ week, or 4 sessions/week of RE, no further significant reduction in total CVD events occurred [40].

Moreover, less than an hour per week RE was associated with a $32 \%$ reduced risk of hypercholesterolemia, a $29 \%$ reduced risk of MetS and a 32\% reduced risk of new onset T2D [3, 4, 75]. However, higher levels of RE failed to produce any benefit in regards to hypercholesterolemia and MetS. Moreover, the upper level of muscular strength showed no significant reduction in T2D incidence [3, 4, 75].

\section{Power of Play}

The benefit our hunter-gatherer ancestors had over modern humans is that they were exercising as a means to live. Occupations have since moved indoors and most "work" is mental, and generally performed while sitting in chairs. So, whereas our ancestors led an active lifestyle out of necessity, our modern lifestyle is generally very sedentary, and PA is now optional and therefore needs to be a personal responsibility. The most successful exercise regimens, just like the most successful diets, are those that are integrated into our lives by choice and not prescription.

Play is a mammalian invention that dates back at least 80 million years. This playful physical interaction with others has been conserved through evolution because it helps to bond us with our fellow mammals, reduces anxiety, hones our agility, and augments physical strength and stamina - all of which improves our odds of surviving in the wild as well in the modern urban jungle. But we mammals are generally compelled to play not because we are consciously trying to reap these benefits to mental and physical health, but rather because play is fun. Therein lies the true power of play-we choose to make it a priority because it enhances our enjoyment of life.

There is a strong body of evidence that suggests the PA done while physically interacting with others-sports such as dancing, badminton, soccer, golf, softball, basketball and tennis-is superior to activity completed alone including swimming, cycling and jogging [19, 47, 69, 73]. Social isolation remains one of the strongest predictors of reduced life expectancy [28]. Moreover, activity done in a natural outdoor environment also bestows additional benefits for health and wellbeing, including reductions in stress levels, elevated mood and enhanced memory [7, 60]. The outdoor PA routines done amongst greenery, trees and bodies of water may too increase adherence to PA more so than indoor routines [72].

Furthermore, the amount of outdoor activity associated with good health and well-being is a mere 120 min per week, with maximal benefits seen at 200-300 min [77]. Humans are evolutionary adapted to be highly social, outdoor creatures and the conglomeration of this data supports that picture. While at face value the fact that badminton may bolster longevity more so than jogging may seem contradictory, it is perfectly in line with what we know about hunter-gatherers.

\section{Conclusion}

Humanity instinctively understands and gravitates towards the ideal exercise regimen; it was crafted and has been finely-tuned over tens-of-thousands of generations and installed into the human genome. Then in flurry of modernization over the last century we abandoned our day-today physically active lifestyles in exchange for an alarming incidence of obesity, T2D, MetS, and CVD. It is now time once again, however, to readopt a lifestyle that kept hunter-gatherer communities virtually free of obesity and chronic non-communicable disease for millennia. Just as the Ache were singing as they trotted along with their fellow tribesman during their hunts, it is not individual subjecting themselves to the solitary 20-mile run who is the recipient of the most $\mathrm{CV}$ benefit, but rather those performing high amounts of low intensity exercise in combination with moderate amounts of moderate to high intensity exercise, with their peers, in an outdoor environment, preferably also with regular sessions of physically interactive play or dancing.

\section{Compliance with Ethical Standards}

Conflict of interest The authors declare that they have no competing interests.

\section{References}

1. Arem H, Moore SC, Patel A, Hartge P, Berrington de Gonzalez A, Visvanathan K, Campbell PT, Freedman M, Weiderpass E, Adami HO, Linet MS, Lee IM, Matthews CE. Leisure time physical activity and mortality: a detailed pooled analysis of the doseresponse relationship. JAMA Intern Med. 2015;175(6):959-67.

2. Armstrong ME, Green J, Reeves GK, Beral V, Cairns BJ. Collaborators Million Women Study. Frequent physical activity may not reduce vascular disease risk as much as moderate activity: large prospective study of women in the United Kingdom. Circulation. 2015;131(8):721-9.

3. Bakker EA, Lee DC, Sui X, Artero EG, Ruiz JR, Eijsvogels TMH, Lavie CJ, Blair SN. Association of resistance exercise, independent of and combined with aerobic exercise, with the incidence of metabolic syndrome. Mayo Clin Proc. 2017;92(8):1214-22.

4. Bakker EA, Lee DC, Sui X, Eijsvogels TMH, Ortega FB, Lee IM, Lavie CJ, Blair SN. Association of resistance exercise with the incidence of hypercholesterolemia in men. Mayo Clin Proc. 2018;93(4):419-28. 
5. Barry VW, Caputo JL, Kang M. The joint association of fitness and fatness on cardiovascular disease mortality: a meta-analysis. Prog Cardiovasc Dis. 2018;61(2):136-41.

6. Bassett DR Jr, Toth LP, LaMunion SR, Crouter SE. Step counting: a review of measurement considerations and health-related applications. Sports Med. 2017;47(7):1303-15.

7. Berman MG, Jonides J, Kaplan S. The cognitive benefits of interacting with nature. Psychol Sci. 2008;19(12):1207-12.

8. Blair SN, Kohl HW 3rd, Barlow CE, Paffenbarger RS Jr, Gibbons LW, Macera CA. Changes in physical fitness and all-cause mortality. A prospective study of healthy and unhealthy men. JAMA. 1995;273(14):1093-8.

9. Booth FW, Lees SJ. Fundamental questions about genes, inactivity, and chronic diseases. Physiol Genom. 2007;28(2):146-57.

10. Bowerman WJ, Harris WE. Jogging: a medically approved fitness program for all ages. 9 th ed. New York: Grosset \& Dunlap; 1967.

11. Byberg L, Melhus H, Gedeborg R, Sundstrom J, Ahlbom A, Zethelius B, Berglund LG, Wolk A, Michaelsson K. Total mortality after changes in leisure time physical activity in 50 year old men: 35 year follow-up of population based cohort. BMJ. 2009;338:b688.

12. CDC. Childhood Obesity Facts-https://www.cdc.gov/healt hyschools/obesity/facts.htm. In: Centers for Disease Control and Prevention, editor. Atlanta, Georgia: Division of Population Health, National Center for Chronic Disease Prevention and Health Promotion; 2018.

13. Cordain L, Gotshall RW, Eaton SB, Eaton SB 3rd. Physical activity, energy expenditure and fitness: an evolutionary perspective. Int J Sports Med. 1998;19(5):328-35.

14. Cornelissen VA, Verheyden B, Aubert AE, Fagard RH. Effects of aerobic training intensity on resting, exercise and post-exercise blood pressure, heart rate and heart-rate variability. J Hum Hypertens. 2010;24:175-82.

15. Das S, O'Keefe JH. Behavioral cardiology: recognizing and addressing the profound impact of psychosocial stress on cardiovascular health. Curr Atheroscler Rep. 2006;8(2):111-8.

16. Disease GBD, Injury Incidence, Prevalence Collaborators. Global, regional, and national incidence, prevalence, and years lived with disability for 310 diseases and injuries, 1990-2015: a systematic analysis for the Global Burden of Disease Study 2015. Lancet. 2016;388(10053):1545-602.

17. Eaton B, Shostak M, Konner M. The first fitness formulaChapter 7. In: The paleolithic prescription: a program of diet and exercise and a design for living. New York: Harper and Rowe; 1988.

18. Elagizi A, Kachur S, Lavie CJ, Carbone S, Pandey A, Ortega FB, Milani RV. An overview and update on obesity and the obesity paradox in cardiovascular diseases. Prog Cardiovasc Dis. 2018;61(2):142-50.

19. Farahmand B, Broman G, de Faire U, Vagero D, Ahlbom A. Golf: a game of life and death-reduced mortality in Swedish golf players. Scand J Med Sci Sports. 2009;19(3):419-24.

20. Foot DK, Lewis RP, Pearson TA, Beller GA. Demographics and cardiology, 1950-2050. J Am Coll Cardiol. 2000;35(5):66B-80B.

21. Gebel K, Ding D, Chey T, Stamatakis E, Brown WJ, Bauman AE. Effect of moderate to vigorous physical activity on all-cause mortality in middle-aged and older australians. JAMA Intern Med. 2015;175(6):970-7.

22. Ghesquiere JL, Karvonen MJ. Some anthropometric and functional dimensions of the pygmy (Kivu Twa). Ann Hum Biol. 1981;8(2):119-34.

23. Grazioli E, Dimauro I, Mercatelli N, Wang G, Pitsiladis Y, Di Luigi L, Caporossi D. Physical activity in the prevention of human diseases: role of epigenetic modifications. BMC Genom. 2017;18(Suppl 8):802.
24. World Bank Group. Life expectancy at birth, total (years). In: Life expectancy. Washington, DC: The World Bank; 2017. https://data. worldbank.org/indicator/sp.dyn.le00.in. Accessed 29 Mar 2020.

25. Hales CM, Fryar CD, Carroll MD, Freedman DS, Ogden CL. Trends in obesity and severe obesity prevalence in US youth and adults by sex and age, 2007-2008 to 2015-2016. JAMA. 2018;319(16):1723-5.

26. Harber MP, Kaminsky LA, Arena R, Blair SN, Franklin BA, Myers J, Ross R. Impact of cardiorespiratory fitness on all-cause and disease-specific mortality: advances since 2009. Prog Cardiovasc Dis. 2017;60(1):11-20.

27. Hottenrott K, Ludyga S, Schulze S. Effects of high intensity training and continuous endurance training on aerobic capacity and body composition in recreationally active runners. J Sports Sci Med. 2012;11(3):483-8.

28. Jetten J, Haslam C, Haslam SA. The social cure: identity, health and well-being. London: Psychology Press; 2011.

29. Kaplan H, Thompson RC, Trumble BC, Wann LS, Allam AH, Beheim B, Frohlich B, Sutherland ML, Sutherland JD, Stieglitz J, Rodriguez DE, Michalik DE, Rowan CJ, Lombardi GP, Bedi R, Garcia AR, Min JK, Narula J, Finch CE, Gurven M, Thomas GS. Coronary atherosclerosis in indigenous South American Tsimane: a cross-sectional cohort study. Lancet. 2017;389(10080):1730-9.

30. Karjalainen J, Kujala UM, Kaprio J, Sarna S, Viitasalo M. Lone atrial fibrillation in vigorously exercising middle aged men: casecontrol study. BMJ. 1998;316(7147):1784-5.

31. Kemi OJ, Wisloff U. High-intensity aerobic exercise training improves the heart in health and disease. J Cardiopulm Rehabil Prev. 2010;30(1):2-11.

32. Kennedy AB, Lavie CJ, Blair SN. Fitness or fatness: which is more important? JAMA. 2018;319(3):231-2.

33. Kodama S, Saito K, Tanaka S, Maki M, Yachi Y, Asumi M, Sugawara A, Totsuka K, Shimano H, Ohashi Y, Yamada N, Sone H. Cardiorespiratory fitness as a quantitative predictor of all-cause mortality and cardiovascular events in healthy men and women: a meta-analysis. JAMA. 2009;301(19):2024-35.

34. Laddu DR, Rana JS, Murillo R, Sorel ME, Quesenberry CP Jr, Allen NB, Gabriel KP, Carnethon MR, Liu K, Reis JP, LloydJones D, Carr JJ, Sidney S. 25-year physical activity trajectories and development of subclinical coronary artery disease as measured by coronary artery calcium: the coronary artery risk development in young adults (CARDIA) study. Mayo Clin Proc. 2017;92(11):1660-70.

35. Lavie CJ, Lee DC, Sui X, Arena R, O'Keefe JH, Church TS, Milani RV, Blair SN. Effects of running on chronic diseases and cardiovascular and all-cause mortality. Mayo Clin Proc. 2015;90(11):1541-52.

36. Lavie CJ, Ozemek C, Carbone S, Katzmarzyk PT, Blair SN. Sedentary behavior, exercise, and cardiovascular health. Circ Res. 2019;124(5):799-815.

37. Lee DC, Pate RR, Lavie CJ, Sui X, Church TS, Blair SN. Leisuretime running reduces all-cause and cardiovascular mortality risk. J Am Coll Cardiol. 2014;64(5):472-81.

38. Lee DC, Sui X, Artero EG, Lee IM, Church TS, McAuley PA, Stanford FC, Kohl HW 3rd, Blair SN. Long-term effects of changes in cardiorespiratory fitness and body mass index on allcause and cardiovascular disease mortality in men: the Aerobics Center Longitudinal Study. Circulation. 2011;124(23):2483-90.

39. Lee IM, Shiroma EJ, Lobelo F, Puska P, Blair SN, Katzmarzyk PT. Effect of physical inactivity on major non-communicable diseases worldwide: an analysis of burden of disease and life expectancy. Lancet. 2012;380(9838):219-29.

40. Liu Y, Lee DC, Li Y, Zhu W, Zhang R, Sui X, Lavie CJ, Blair SN. Associations of resistance exercise with cardiovascular disease morbidity and mortality. Med Sci Sports Exerc. 2019;51(3):499-508. 
41. Lloyd-Jones DM, Hong Y, Labarthe D, Mozaffarian D, Appel LJ, Van Horn L, Greenlund K, Daniels S, Nichol G, Tomaselli GF, Arnett DK, Fonarow GC, Ho PM, Lauer MS, Masoudi FA, Robertson RM, Roger V, Schwamm LH, Sorlie P, Yancy CW, Rosamond WD. Defining and setting national goals for cardiovascular health promotion and disease reduction: the American Heart Association's strategic Impact Goal through 2020 and beyond. Circulation. 2010;121(4):586-613.

42. Loy SF, Hoffmann JJ, Holland GJ. Benefits and practical use of cross-training in sports. Sports Med. 1995;19(1):1-8.

43. McArdle WD, Katch FI, Katch VL. Exercise physiology: energy, nutrition, and human performance. Philadelphia, PA: Wolters Kluwer/Lippincott Williams \& Wilkins Health; 2010.

44. Mohlenkamp S, Lehmann N, Breuckmann F, Brocker-Preuss M, Nassenstein K, Halle M, Budde T, Mann K, Barkhausen J, Heusch G, Jockel KH, Erbel R, Investigators Marathon Study, and Investigators Heinz Nixdorf Recall Study. Running: the risk of coronary events: prevalence and prognostic relevance of coronary atherosclerosis in marathon runners. Eur Heart J. 2008;29(15):1903-10.

45. Mons U, Hahmann H, Brenner H. A reverse J-shaped association of leisure time physical activity with prognosis in patients with stable coronary heart disease: evidence from a large cohort with repeated measurements. Heart. 2014;100(13):1043-9.

46. Moore SC, Patel AV, Matthews CE, Berrington de Gonzalez A, Park Y, Katki HA, Linet MS, Weiderpass E, Visvanathan K, Helzlsouer KJ, Thun M, Gapstur SM, Hartge P, Lee IM. Leisure time physical activity of moderate to vigorous intensity and mortality: a large pooled cohort analysis. PLoS Med. 2012;9(11):e1001335.

47. Muller P, Rehfeld K, Schmicker M, Hokelmann A, Dordevic M, Lessmann V, Brigadski T, Kaufmann J, Muller NG. Evolution of neuroplasticity in response to physical activity in old age: the case for dancing. Front Aging Neurosci. 2017;9:56.

48. O'Keefe EL, Torres-Acosta N, O'Keefe JH, Lavie CJ. Training for longevity: the reverse J-curve for exercise. Mo Med. 2020;117(4):355-61.

49. O'Keefe JH, Franklin B, Lavie CJ. Exercising for health and longevity vs peak performance: different regimens for different goals. Mayo Clin Proc. 2014;89(9):1171-5.

50. O'Keefe JH, Lavie CJ. Run for your life... at a comfortable speed and not too far. Heart. 2013;99(8):516-9.

51. O'Keefe JH, Lavie CJ, Schnohr P. Dosing exercise for longevity: how much is enough and how much is too much? J S C Med Assoc. 2016;112(2):191-6.

52. O'Keefe JH, O'Keefe EL, Lavie CJ. The goldilocks zone for exercise: not too little, not too much. Mo Med. 2018;115(2):98-105.

53. O'Keefe JH, Patil HR, Lavie CJ, Magalski A, Vogel RA, McCullough PA. Potential adverse cardiovascular effects from excessive endurance exercise. Mayo Clin Proc. 2012;87(6):587-95.

54. O'Keefe JH, Schnohr P, Lavie CJ. The dose of running that best confers longevity. Heart. 2013;99(8):588-90.

55. O'Keefe JH, Vogel R, Lavie CJ, Cordain L. Achieving huntergatherer fitness in the 21(st) century: back to the future. Am J Med. 2010;123(12):1082-6.

56. O'Keefe JH, Vogel R, Lavie CJ, Cordain L. Exercise like a huntergatherer: a prescription for organic physical fitness. Prog Cardiovasc Dis. 2011;53(6):471-9.

57. ODPHP. Healthy People 2020. 2019. https://www.healthypeople. gov/. Accessed 23 July 2019.

58. Ozemek C, Laddu DR, Lavie CJ, Claeys H, Kaminsky LA, Ross R, Wisloff U, Arena R, Blair SN. An update on the role of cardiorespiratory fitness, structured exercise and lifestyle physical activity in preventing cardiovascular disease and health risk. Prog Cardiovasc Dis. 2018;61(5-6):484-90.
59. Patil HR, O’Keefe JH, Lavie CJ, Magalski A, Vogel RA, McCullough PA. Cardiovascular damage resulting from chronic excessive endurance exercise. Mo Med. 2012;109(4):312-21.

60. Peplonska B, Lissowska J, Hartman TJ, Szeszenia-Dabrowska N, Blair A, Zatonski W, Sherman ME, Garcia-Closas M, Brinton LA. Adulthood lifetime physical activity and breast cancer. Epidemiology. 2008;19(2):226-36.

61. Prentice TW. Health, history, and hard choices: funding dilemmas in a fast-changing world-World Health Organization. NVSQ. 2008;37:63S-75S.

62. Rideout VJ, Foehr UG, Roberts DF. Generation M2: media in the lives of 8- to 18-year-olds: a Kaiser Family Foundation Study. In: Henry J, editor. Kaiser Family Foundation. Menlo Park: Henry J Kaiser Family Foundation; 2010.

63. Ritchie H, Roser M. Causes of death. 2019. https://ourworldin data.org/causes-of-death. In Our World in Data. University of Oxford: University of Oxford.

64. Rozanski A, Blumenthal JA, Davidson KW, Saab PG, Kubzansky L. The epidemiology, pathophysiology, and management of psychosocial risk factors in cardiac practice: the emerging field of behavioral cardiology. J Am Coll Cardiol. 2005;45(5):637-51.

65. Saint-Maurice PF, Troiano RP, Bassett DR Jr, Graubard BI, Carlson SA, Shiroma EJ, Fulton JE, Matthews CE. Association of daily step count and step intensity with mortality among US adults. JAMA. 2020;323(12):1151-60.

66. Sandvik L, Erikssen J, Thaulow E, Erikssen G, Mundal R, Rodahl $\mathrm{K}$. Physical fitness as a predictor of mortality among healthy, middle-aged Norwegian men. N Engl J Med. 1993;328(8):533-7.

67. Schnohr P, Marott JL, Lange P, Jensen GB. Longevity in male and female joggers: the Copenhagen City Heart Study. Am J Epidemiol. 2013;177(7):683-9.

68. Schnohr P, Marott JL, O'Keefe JH. Reply: exercise and mortality reduction: recurring reverse J- or U-curves. J Am Coll Cardiol. 2015;65(24):2674-6.

69. Schnohr P, O'Keefe JH, Holtermann A, Lavie CJ, Lange P, Jensen GB, Marott JL. Various leisure-time physical activities associated with widely divergent life expectancies: the Copenhagen City Heart Study. Mayo Clin Proc. 2018;93(12):1775-85.

70. Schnohr P, O'Keefe JH, Marott JL, Lange P, Jensen GB. Dose of jogging and long-term mortality: the Copenhagen City Heart Study. J Am Coll Cardiol. 2015;65(5):411-9.

71. Schwartz RS, Kraus SM, Schwartz JG, Wickstrom KK, Peichel G, Garberich RF, Lesser JR, Oesterle SN, Knickelbine T, Harris KM, Duval S, Roberts WO, O'Keefe JH. Increased coronary artery plaque volume among male marathon runners. Mo Med. 2014;111(2):89-94.

72. Simonsick EM, Guralnik JM, Volpato S, Balfour J, Fried LP. 'Just get out the door! Importance of walking outside the home for maintaining mobility: findings from the women's health and aging study. J Am Geriatr Soc. 2005;53(2):198-203.

73. Tolahunase M, Sagar R, Dada R. Erratum to "Impact of yoga and meditation on cellular aging in apparently healthy individuals: a prospective, open-label single-arm exploratory study". Oxid Med Cell Longev. 2017;2017:2784153.

74. Trapp EG, Chisholm DJ, Freund J, Boutcher SH. The effects of high-intensity intermittent exercise training on fat loss and fasting insulin levels of young women. Int J Obes (Lond). 2008;32(4):684-91.

75. Wang Y, Lee DC, Brellenthin AG, Sui X, Church TS, Lavie CJ, Blair SN. Association of muscular strength and incidence of type 2 diabetes. Mayo Clin Proc. 2019;94(4):643-51.

76. White LJ, Dressendorfer RH, Muller SM, Ferguson MA. Effectiveness of cycle cross-training between competitive seasons in female distance runners. J Strength Cond Res. 2003;17(2):319-23.

77. White MP, Alcock I, Grellier J, Wheeler BW, Hartig T, Warber SL, Bone A, Depledge MH, Fleming LE. Spending at least 120 
minutes a week in nature is associated with good health and wellbeing. Sci Rep. 2019;9(1):7730.

78. Williams PT, Thompson PD. Increased cardiovascular disease mortality associated with excessive exercise in heart attack survivors. Mayo Clin Proc. 2014;89(9):1187-94.
79. Yamauchi T, Sato H, Kawamura K. Nutritional status, activity patten, and dietary intake among the Baka Hunter-Gatherers in the village camps in Cameroon. Afr Study Monogr. 2000;21:67-82. 